\title{
Acetylcholine induces contractile and relaxant effects in canine nasal venous
}

\section{systems}

\author{
M. Wang and M.A. Lung
}

ABSTRACT: Acetylcholine (ACh) induces nasal congestion at low doses but decongestion at high doses. The current study investigated the vascular mechanisms underlying this biphasic nasal airway response in dogs.

Collecting and outflow veins from anterior and posterior nasal venous systems and the septal mucosa (containing sinusoidal venous plexuses) were isolated. The in vitro isometric tension of the vascular segments was monitored to reflect vascular reactivity. Immunohistochemical localisation of reduced nicotinamide adenine dinucleotide phosphate (NADPH)-diaphorase and endothelial nitric oxide synthase (eNOS) was performed.

$\mathrm{ACh}$ did not affect the venous plexuses but contracted the anterior collecting vein and the outflow veins of both systems in a concentration-dependent manner; the responses were unaffected by nitro-L-arginine-methyl-ester (L-NAME). ACh relaxed posterior collecting veins at low concentrations but contracted them at higher concentrations; L-NAME enhanced the contractions but inhibited the relaxations, with the inhibition reversed by L-arginine. NADPHdiaphorase and eNOS were located predominantly in the posterior collecting veins.

The fact that acetylcholine at low concentrations relaxes posterior collecting veins but contracts other collecting and outflow veins implies that the agonist in vivo may induce nasal congestion by increasing posterior blood volume. At higher concentrations, acetylcholine contracts posterior collecting veins as well, implying diminished blood volume in both venous systems, and consequently nasal decongestion. The induced contraction in posterior collecting veins is nitric oxide-independent, while the induced relaxation is nitric oxide-dependent.

KEYWORDS: Acetylcholine, nasal venous vessels, nitric oxide, vasocontraction, vasorelaxation

$\mathbf{N}$ asal obstruction, one of the cardinal signs of rhinitis, is commonly believed to be due to blood congestion in the venous sinusoids of the nasal mucosa [1]. Anteriorly, venous blood is drained via the high-pressure and high-flow dorsal nasal vein (DNV), while posteriorly it is drained via the low-pressure and low-flow sphenopalatine vein (SPV) $[2,3]$. The collecting and outflow veins of both systems are large and highly muscular in nature. Since the collecting veins are located within the nasal cavity, their dilatation can considerably increase mucosal blood volume [3]. The outflow veins are situated outside the nasal cavity and their dilatation will favour venous outflow [3]. Mucosal congestion, thereby nasal obstruction, may be related to dilatation of venous sinusoids and/or collecting veins and constriction of outflow veins. Opposite changes in the mechanisms would lead to mucosal decongestion and relief of nasal obstruction.
The current authors have previously studied the action of acetylcholine (ACh; $5 \times 10^{-4}-50 \mu \mathrm{g} \cdot \mathrm{kg}^{-1}$. $\mathrm{min}^{-1}$, intra-arterially) on nasal airway resistance in anaesthetised dogs [4]. The doses given did not elicit systemic effects, indicating that the doses are within the physiological dose range and the responses are probably the local effects of the autacoid on the nasal vasculature. ACh, in doses of $<5 \mu \mathrm{g} \cdot \mathrm{kg}^{-1} \cdot \mathrm{min}^{-1}$, increases nasal airway resistance; the posterior venous outflow is increased while the anterior venous outflow is decreased in noses with constant-flow vascular perfusion. In doses $>5 \mu \mathrm{g} \cdot \mathrm{kg}^{-1} \cdot \mathrm{min}^{-1}$, ACh decreases nasal airway resistance; both venous outflows are increased whether the nose is subject to spontaneous blood flow or constant-flow vascular perfusion. The results indicate that ACh probably exerts differential action on different components of the nasal vascular bed in a dose-dependent manner.

\section{AFFILIATIONS}

Dept of Physiology, Faculty of Medicine, University of Hong Kong, Pokfulam, Hong Kong Special Administrative Region (SAR), China

\section{CORRESPONDENCE}

M.A. Lung

Dept of Physiology

University of Hong Kong

Faculty of Medicine Building

21 Sassoon Road

Pokfulam

Hong Kong SAR

China

Fax: 85228559730

E-mail: makylung@hkucc.hku.hk

Received:

June 292005

Accepted after revision:

May 162006

SUPPORT STATEMENT

The present study was supported by a Research Grants Council grant (HKU373/94M) from the Hong Kong SAR Government and a Committee on Research and Conference Grants grant $(335 / 034 / 0067)$ from the University of Hong Kong presented to M. A. Lung. 
In order to elucidate the probable vascular mechanisms underlying the biphasic muscarinic control of nasal airway resistance, the current in vitro study investigated the action of exogenous ACh on the different segments of the two nasal venous systems.

\section{METHODS}

\section{Tissue preparation}

The Committee on the Use of Live Animals for Teaching and Research of the University of Hong Kong approved the study. Mongrel dogs (weighing 15-25 kg) of either sex were anaesthetised with pentobarbital sodium $\left(30 \mathrm{mg} \cdot \mathrm{kg}^{-1}, i . v\right.$. $)$ and then killed by an overdose of the same anaesthetic (200 $\mathrm{mg} \cdot \mathrm{kg}^{-1}$, i.v.). DNV, anterior collecting vein (ACV), SPV, lateral collecting vein (LCV), septal collecting vein (SCV) and septal mucosa (SM) were isolated from the nasal cavity (fig. 1). The diameters of the vessels were: $3.5-4.5 \mathrm{~mm}$ for LCV; $1.5-$ $2.5 \mathrm{~mm}$ for SCV; $0.5-1 \mathrm{~mm}$ for ACV; $2-3 \mathrm{~mm}$ for DNV; and $0.5-1.5 \mathrm{~mm}$ for SPV. The SM contained a network of venous sinusoidal vessels of diameters ranging from $0.1-0.5 \mathrm{~mm}$ [3]. All segments were immediately immersed in chilled and aerated $\left(95 \% \mathrm{O}_{2}: 5 \% \mathrm{CO}_{2}\right)$ Krebs-Ringer bicarbonate solution. The composition of the solution was (mM): $119 \mathrm{NaCl}, 4.7 \mathrm{KCl}$, $2.5 \mathrm{CaCl}_{2}\left(\mathrm{CaCl}_{2} \cdot 6 \mathrm{H}_{2} \mathrm{O}\right), 1.2 \mathrm{KH}_{2} \mathrm{PO}_{4}, 1.2 \mathrm{MgSO}_{4}\left(\mathrm{MgSO}_{4}\right.$. $\left.7 \mathrm{H}_{2} \mathrm{O}\right), 25 \mathrm{NaHCO}_{3}, 0.026$ calcium disodium EDTA and 11.1 glucose; pH 7.4 (238 pH/Blood Gas Analyzer; Ciba-Corning, East Walpole, MA, USA). One vascular ring of $4 \mathrm{~mm}$ in length from each blood vessel and a strip of $6 \mathrm{~mm}$ in length and $6 \mathrm{~mm}$ in width from the SM were removed for experimentation. Care was taken to minimise rubbing of the intimal surface when preparing rings, in order to keep an intact and functional endothelium. The functional integrity of the endothelium was determined by the presence of a relaxation to calcium ionophore A23187 $\left(1 \times 10^{-7} \mathrm{M}\right)$ in phenylephrine (PE)-precontracted segments at the end of the experiment.

\section{Tissue bath studies}

The venous ring or mucosal strip was suspended in an organ chamber filled with $5 \mathrm{~mL}$ modified Krebs-Ringer bicarbonate

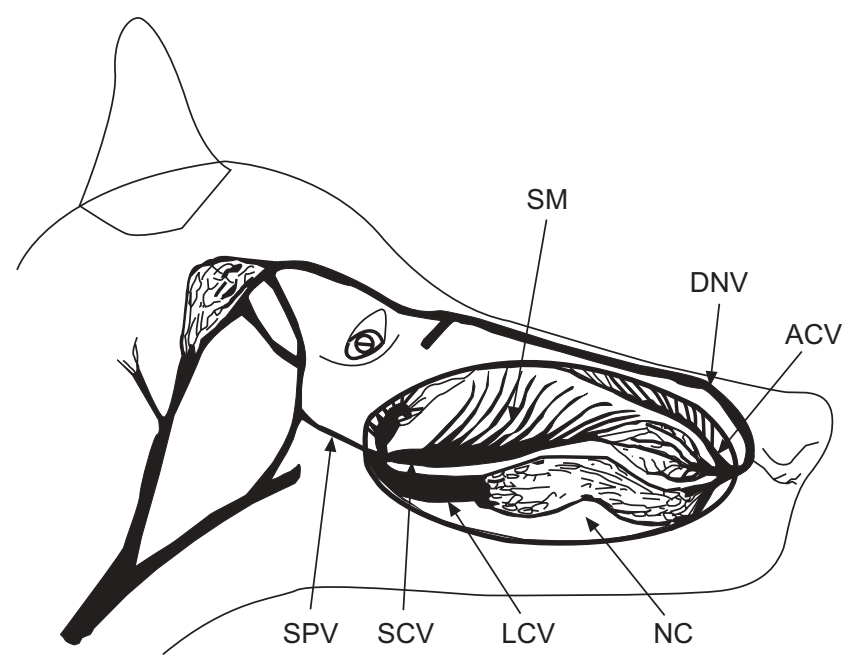

FIGURE 1. Diagrammatic illustration of the locations of the nasal venous vessels. ACV: anterior collecting vein; DNV: dorsal nasal vein; SM: septal mucosa; LCV: lateral collecting vein; SCV: septal collecting vein; SPV: sphenopalatine vein; NC: nasal cavity. solution, which was bubbled with $95 \% \quad \mathrm{O}_{2}: 5 \% \quad \mathrm{CO}_{2}$ and maintained at $37^{\circ} \mathrm{C}$. The tissue segment was connected to a Grass FT03 force displacement transducer (Grass-Telefactor, West Warwick, RI, USA) and changes in isometric force were recorded and fed to a computer. After a 30-min equilibrium period, the tissue segment was stretched to its optimal resting tension as previously described [5]. The optimal resting tension was determined in preliminary experiments by constructing the length-tension relationship of the isolated tissue segment. The optimal tensions used to set up various tissue segments were as follows: $2.0 \mathrm{~g}$ for $\mathrm{LCV} ; 1.5 \mathrm{~g}$ for SCV; $1.0 \mathrm{~g}$ for $\mathrm{ACV}$; $1.5 \mathrm{~g}$ for DNV; $1.0 \mathrm{~g}$ for SPV; and $1.0 \mathrm{~g}$ for SM. The tissue was allowed to equilibrate for another $60 \mathrm{~min}$, with washes every $20 \mathrm{~min}$ during the equilibration period. The tissue segment was then exposed to $80 \mathrm{mM} \mathrm{KCl}$ until two reproducible contractions (variation $<10 \%$ ) developed. Nicotinic ACh receptors have been found to be present in sensory nerve endings [6] and vascular endothelial cells [7]. In order to eliminate any nicotinic effects that may be elicited if nicotinic $\mathrm{ACh}$ receptors are present in the nasal vascular ring or strip, an inhibitor of nicotinic receptor (hexamethonium $1 \times 10^{-5} \mathrm{M}$ ) was added to the tissue bath after the washout of $\mathrm{KCl}$ and $30 \mathrm{~min}$ before a protocol began. An inhibitor of acetylcholinesterase (echothiophate $1 \times 10^{-7} \mathrm{M}$ ) was also added $[8,9]$. At the end of an experiment, the maximal relaxation or passive tone of the vessel was determined by adding a maximal dose of $\mathrm{NaNO}_{2}$ $\left(5 \times 10^{-2} \mathrm{M}\right)$ [10]. The total active tone $(\mathrm{TAT})$ in the present study was defined as the difference between the tone at $80 \mathrm{mM}$ $\mathrm{KCl}$ and the tone at $5 \times 10^{-2} \mathrm{M} \mathrm{NaNO}_{2}$.

\section{Study design}

To assess the effects of exogenous ACh on the nasal venous vessels, the agonist was cumulatively added to the tissue bath in 10-fold increments until a maximal response was attained. In preliminary studies, the preparation was subjected to fullrange $\mathrm{ACh}$ challenge several times at 30 -min intervals. The responses were reproducible, with minimal changes in tissue sensitivity to ACh over the time course of the experiment. The cumulative ACh concentration-response curve was established with the tissue held at resting tension and also at raised tone. $\mathrm{PE}$ at concentrations ranging $1 \times 10^{-7}-1 \times 10^{-5} \mathrm{M}$ was used to raise the tension to $\sim 70 \% \mathrm{TAT}$.

To study whether the response to ACh was nitric oxide (NO)dependent, a cumulative concentration-response curve was determined after the tissue was incubated for 30 min with either: the vehicle; nitro-L-arginine-methyl-ester (L-NAME; an NO synthase (NOS) inhibitor) alone; or L-NAME in combination with L-arginine (a NOS substrate) $[11,12]$. The concentration of L-NAME $\left(1 \times 10^{-5} \mathrm{M}\right)$ used was found to be effective in inhibiting the relaxation induced by calcium ionophore A23187 $\left(1 \times 10^{-9}-1 \times 10^{-3} \mathrm{M}\right)$ in PE-pre-contracted vascular segments. The concentration of L-arginine $\left(1 \times 10^{-2}-3 \times 10^{-2} \mathrm{M}\right)$ given was sufficient to prevent the inhibition caused by L-NAME in A23187-induced relaxation.

\section{Immunohistochemistry}

The isolated venous vessels were washed with ice-cold PBS ( $\mathrm{pH} 7.4$ ) for $5 \mathrm{~min}$ and then fixed with $4 \%$ paraformaldehyde in PBS overnight at $4{ }^{\circ} \mathrm{C}$. The fixed tissues were washed thoroughly in PBS and immersed in PBS which contained $20 \%$ 
sucrose and $0.1 \%$ sodium azide overnight at $4{ }^{\circ} \mathrm{C}$. The tissue blocks were trimmed, embedded (Tissue-Tek OCT; Sakura Finetek, Tokyo, Japan) and stored in liquid nitrogen until sectioned. Cryostat sections (16-20 $\mu \mathrm{m}$ in thickness) were warmed to room temperature, rinsed in PBS twice and then air-dried.

Immunolocalisation of multiple NOS isoforms was performed using reduced nicotinamide adenine dinucleotide phosphate (NADPH)-diaphorase staining [13]. The sections were incubated in a moist chamber at $37^{\circ} \mathrm{C}$ in the dark for $90 \mathrm{~min}$ with a solution containing nitroblue tetrazolium $\left(0.1 \mathrm{mg} \cdot \mathrm{mL}^{-1}\right), \beta$ NADPH $\left(0.5 \mathrm{mg} \cdot \mathrm{mL}^{-1}\right)$ and Triton $X-100(0.3 \%)$ in PBS ( $\mathrm{pH}$ 7.3). The reaction was stopped by washing with PBS. Sections were counter-stained with $1 \%$ neutral red for $30 \mathrm{~s}$, washed with distilled water, dehydrated through graded alcohols, cleared in toluene, mounted in resin and examined and photographed under a light microscope.

Immunohistochemical localisation of endothelial NOS (eNOS) isoforms was performed [13]. Rabbit polyclonal antibodies for eNOS that are reactive to canine tissues (PA1-037; Affinity BioReagents, Golden, CO, USA) were used. Staining was performed using the Vectastain Elite ABC kits (Vector Laboratories, Burlingame, CA, USA). To quench endogenous peroxidase activity, the sections were incubated for $30 \mathrm{~min}$ with $0.9 \%$ hydrogen peroxide in $60 \%$ methanol: $40 \%$ PBS. To block nonspecific staining, the sections were incubated for $20 \mathrm{~min}$ with $10 \%$ blocking serum. After blotting excess blocking serum from the sections, the sections were incubated for $18 \mathrm{~h}$ at $4^{\circ} \mathrm{C}$ with primary antiserum (1:1000) diluted with blocking serum. After rinsing three times with PBS, the sections were incubated for $60 \mathrm{~min}$ with biotinylated secondary antibodies (1:200). After three further rinses with PBS, the sections were incubated for $60 \mathrm{~min}$ with Vectastain $A B C$ reagents (1:200). The sections were washed once with PBS and then incubated for $7 \mathrm{~min}$ with diaminobenzidine substrate solution. The reaction was stopped by rinsing in distilled water. The sections were dehydrated through graded alcohols, cleared in toluene, mounted in resin and examined and photographed under a light microscope.

\section{Drugs}

The following drugs were used: A23187 (Sigma-Aldrich, St Louis, MO, USA), ACh chloride (Sigma); echothiophate iodide (Ayerst Laboratories, St Davids, PA, USA); hexamethonium bromide (Sigma); L-NAME (Sigma); L-arginine hydrochloride (Sigma); phenylephrine hydrochloride (Sigma); and sodium nitrite (Sigma).

All solutions were freshly prepared before each experiment by dissolving the compounds in distilled water. All drugs were added in volumes of $15 \mu \mathrm{L}$, i.e. $0.3 \%$ of the organ bath volume. Identical volumes of the drug vehicle had no effect on all tissue preparations. Concentrations of agents were expressed as the final concentration in the tissue bath.

\section{Analysis of data}

All responses were expressed as a per cent of TAT of the same tissue. Data are presented as mean \pm SEM; $n$ refers to the number of animals. Comparison of concentration-response curves was performed using repeated measures ANOVA.
When the F-test was significant, the Bonferonni test was used to determine the concentration at which the responses were statistically different. The maximal response elicited (Emax), the concentration required to achieve half response (EC50) and potency $\left(\mathrm{pD}_{2}\right)$ value $(\mathrm{pEC} 50=-\log E \mathrm{C} 50)$ were calculated Comparison of Emax and $\mathrm{pD}_{2}$ values between groups was performed with one-way ANOVA followed by the StudentNewman-Keuls test. A p-value of 0.05 was considered to be significant.

\section{RESULTS}

\section{Exogenous ACh-induced responses in tissues at resting tension}

At resting tension, ACh caused relaxation at concentrations of $1 \times 10^{-9}-1 \times 10^{-3} \mathrm{M}$ but contraction at higher concentrations $\left(\geqslant 1 \times 10^{-2} \mathrm{M}\right)$ in $\mathrm{LCV}$ and SCV $(\mathrm{p}<0.05$, maximal response versus baseline). ACh caused concentration-dependent contraction in ACV, DNV and SPV $(\mathrm{p}<0.05$, maximal response versus baseline), but had no significant action on $\mathrm{SM}$ at all concentrations (maximal response versus baseline; fig. 2a).
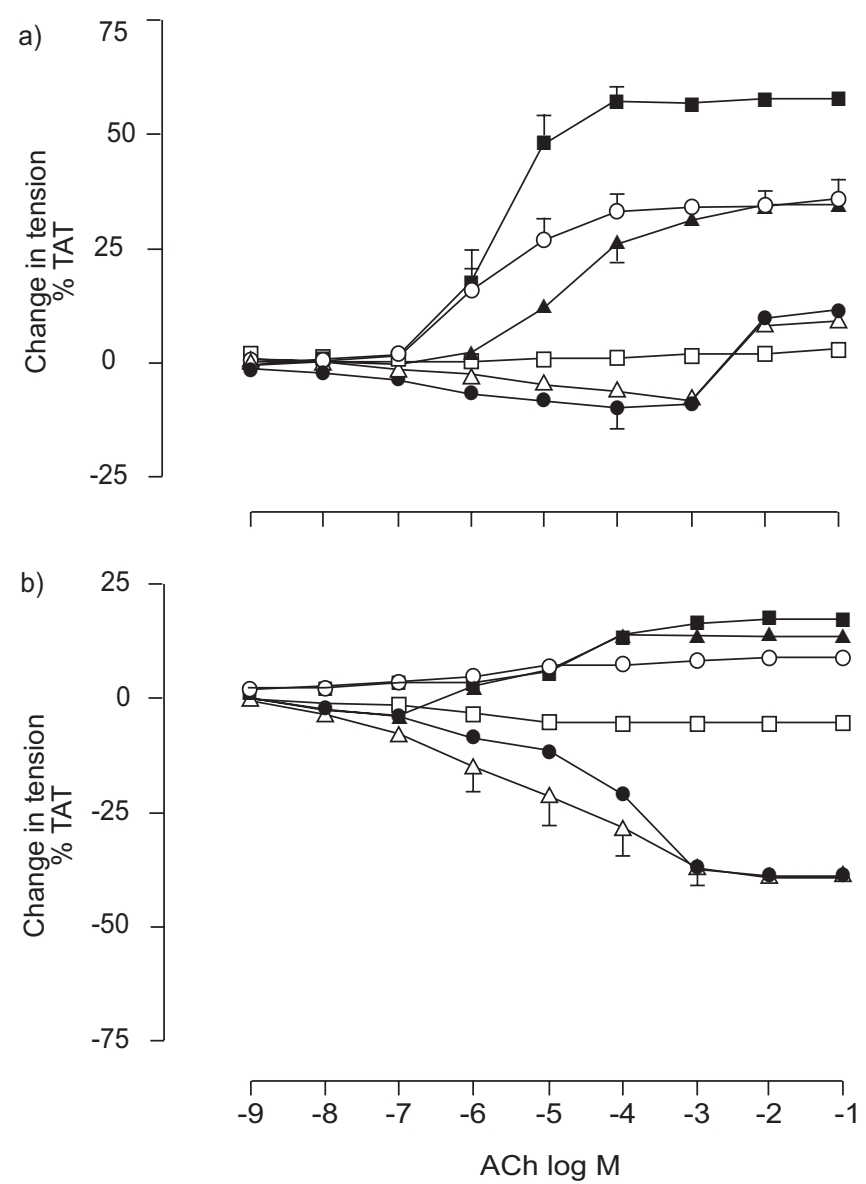

FIGURE 2. The effects of acetylcholine (ACh) on nasal venous vessels at a) resting tension and $b$ ) phenylephrine-raised tone. Data are presented as mean \pm SEM. TAT: total active tone. $\bullet$ : lateral collecting vein (a: $n=9 ; b: n=8) ; \triangle$ septal collecting vein (a: $n=6 ; b: n=7) ; 0$ : anterior collecting vein ( $a: n=5 ; b: n=7$ ) 口: dorsal nasal vein (a: $n=6 ; b: n=7) ; \boldsymbol{\Lambda}$ : sphenopalatine vein $(a: n=8 ; b: n=11)$; $\square$ : septal mucosa (a: $n=5 ; b: n=7$ ). 
TABLE 1 Potency $\left(\mathrm{pD}_{2}\right)$ and maximal response (Emax; \% total active tone) values for acetylcholine (ACh) in control and different experimental groups of nasal venous vessels at resting tension and raised tone

\begin{tabular}{|c|c|c|c|c|c|c|}
\hline & \multicolumn{2}{|c|}{ Control } & \multicolumn{2}{|c|}{ L-NAME } & \multicolumn{2}{|c|}{ L-NAME+L-arginine } \\
\hline & $\mathrm{pD}_{2}$ & Emax \% & $\mathrm{pD}_{2}$ & Emax \% & $\mathrm{pD}_{2}$ & Emax \% \\
\hline LCV $\leqslant 10^{-3} \mathrm{M}^{\#}$ & $6.1 \pm 0.19(9)$ & $-10 \pm 1.5(9)$ & & $-1 \pm 1.6^{\star}(9)$ & NA & NA \\
\hline$S C V \leqslant 10^{-3} M^{\#}$ & $6.0 \pm 0.21$ & $-8 \pm 2.5(6)$ & & $0 \pm 0^{*}(6)$ & NA & NA \\
\hline$L C V \geqslant 10^{-2} M^{\#}$ & $2.3 \pm 0.03(9)^{+}$ & $12 \pm 2.0(9)^{+}$ & $2.4 \pm 0.029$ ) & $19 \pm 1.9(9)^{*}$ & NA & NA \\
\hline $\mathrm{DNV}^{\#}$ & $5.7 \pm 0.23^{\S}(6)$ & $58 \pm 2.4^{\S}(6)$ & $5.9 \pm 3.6(6)$ & $55 \pm 6.2(6)$ & NA & NA \\
\hline $\mathbf{S P V}^{\#}$ & $4.9 \pm 0.12(8)^{5}$ & $35 \pm 2.1(8)^{5}$ & $5.2 \pm 0.10(8)$ & $34 \pm 4.2(8)$ & NA & NA \\
\hline LCV & $4.7 \pm 0.14(13)^{+}$ & $-38 \pm 2.0(13)^{+}$ & $4.5 \pm 0.19(5)$ & $-11 \pm 2.7(5)^{\star}$ & $4.7 \pm 0.19$ & $-33 \pm 2.8(5)^{f}$ \\
\hline scv & $4.9 \pm 0.21(12)^{+}$ & $-39 \pm 3.5(12)^{+}$ & $4.8 \pm 0.28(6)$ & $-8 \pm 2.3(6)^{\star}$ & $5.1 \pm 0.20$ & $-35 \pm 4.5(5)^{f}$ \\
\hline
\end{tabular}

Data are presented as mean \pm SEM (n). L-NAME: nitro-L-arginine-methyl-ester $1 \times 10^{-5} \mathrm{M}$; LCV: lateral collecting vein; SCV: septal collecting vein; ACV: anterior collecting vein; DNV: dorsal nasal vein; SPV: sphenopalatine vein; NA: not available. ${ }^{\#}$ : vascular segment at resting tension; ": vascular segment at raised tone; ${ }^{+}: p<0.05$ versus LCV and SCV at $\leqslant 1 \times 10^{-3} \mathrm{MACh}$ at resting tension; ${ }^{5}: \mathrm{p}<0.05$ versus LCV and SCV at $\geqslant 1 \times 10^{-2} \mathrm{M}$ ACh at resting tension. ${ }^{f}: \mathrm{p}<0.05$ versus L-NAME-treated group. * $p<0.05$ versus control group. L-arginine was used at a concentration of $3 \times 10^{-2} \mathrm{M}$.

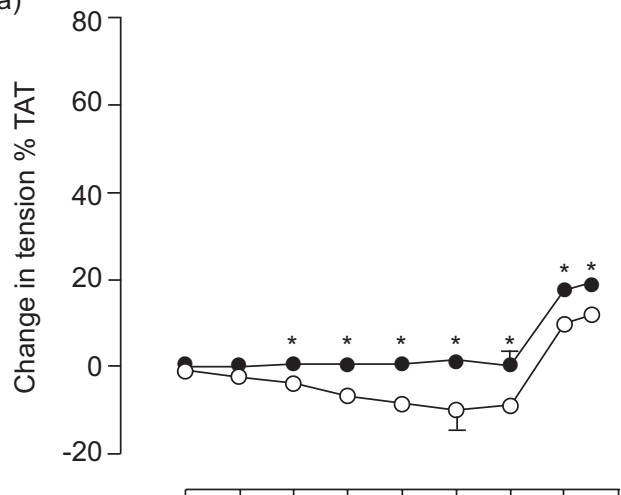

d)

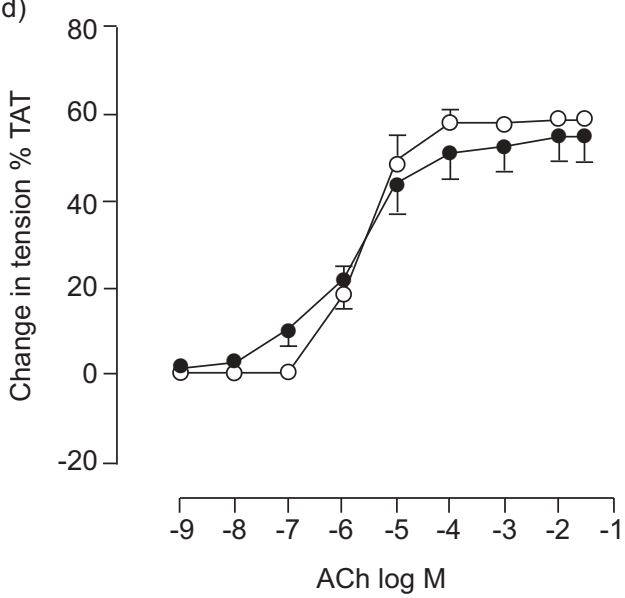

b)

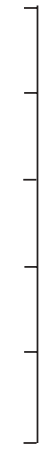

e)

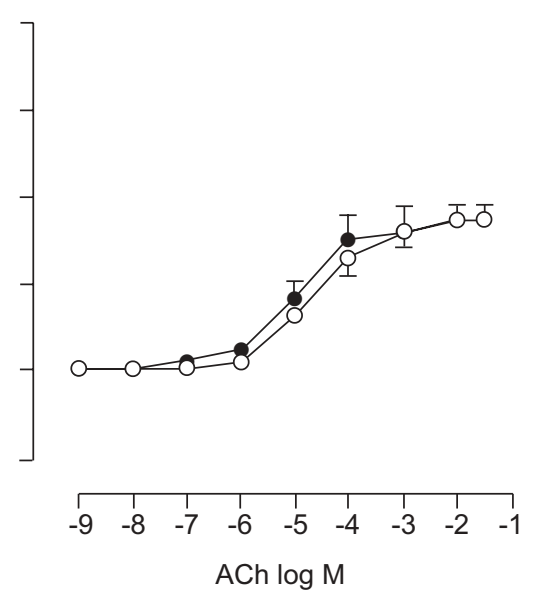

c)

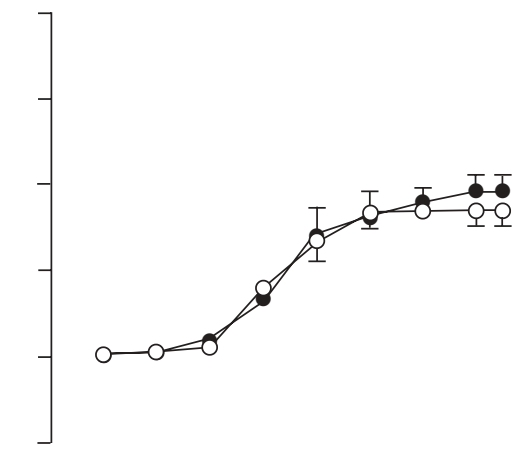

f)

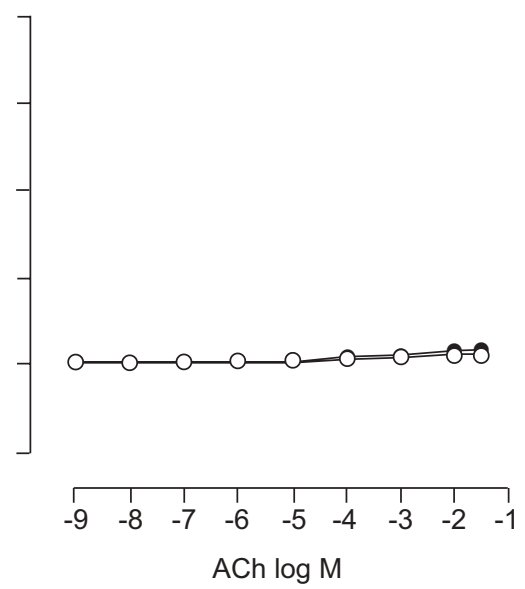

FIGURE 3. The effects of $10^{-5} \mathrm{M}$ nitro-L-arginine-methyl-ester (L-NAME) on the responses of a) lateral collecting vein $(n=9)$, b) septal collecting vein $(n=8)$, c) anterior collecting vein $(n=5)$, d) dorsal nasal vein $(n=6)$, e) sphenopalatine vein $(n=8)$, and f) septal mucosa $(n=5)$ to acetylcholine (ACh) at resting tension. Data are presented as mean \pm SEM. TAT: total active tone. $O$ : control; $\bullet$ : L-NAME $1 \times 10^{-5}$ M. *: $p<0.05$ versus corresponding control. 
$\mathrm{pD}_{2}$ and Emax values for relaxation were not significantly different between LCV and SCV (table 1). For contraction, both $\mathrm{pD}_{2}$ and Emax values were larger in $\mathrm{ACV}, \mathrm{DNV}$ and SPV than in LCV and SCV (table 1).

\section{Exogenous ACh-induced responses in tissues at PE-raised tension}

At PE-raised tone, the response patterns of ACV, DNV, SPV and $\mathrm{SM}$ to $\mathrm{ACh}$ were similar to those at resting tension, i.e. contraction in ACV, DNV and SPV and insignificant action in $\mathrm{SM}$ (fig. 2b). However, the magnitudes of contraction were smaller than at resting tension $(p<0.05)$.

At PE-raised tone, the response patterns of LCV and SCV to $\mathrm{ACh}$ were different from those at resting tension. $\mathrm{ACh}$ produced concentration-dependent relaxation in LCV and SCV and the small contraction at high concentrations of ACh was not seen (fig. $2 b$ ). In LCV and $S C V$, similar $\mathrm{pD}_{2}$ and Emax values were found (table 1 ). The ACh-induced relaxation in LCV and SCV at PE-raised tone was larger and with a much lower $\mathrm{pD}_{2}$ value than at resting tension $(\mathrm{p}<0.05)$.

\section{The effects of L-NAME on responses of nasal blood vessels to $\mathrm{ACh}$}

L-NAME $\left(1 \times 10^{-5} \mathrm{M}\right)$ increased the mean \pm SEM resting tension of LCV (from $1.6 \pm 0.08$ to $2.6 \pm 0.07 \mathrm{~g} ; \mathrm{n}=9 ; \mathrm{p}<0.05$ ), SCV (from $1.1 \pm 0.08$ to $1.6 \pm 0.11 \mathrm{~g} ; \mathrm{n}=8 ; \mathrm{p}<0.05$ ), $\mathrm{ACV}$ (from $0.9 \pm 0.07$ to $1.1 \pm 0.03 \mathrm{~g} ; \mathrm{n}=5 ; \mathrm{p}<0.05$ ), SPV (from $1.1 \pm 0.05$ to $1.4 \pm 0.08 \mathrm{~g}$; $\mathrm{n}=8 ; \mathrm{p}<0.05$ ) and DNV (from $1.5 \pm 0.06$ to $1.8 \pm 0.06 \mathrm{~g} ; \mathrm{n}=6$; $\mathrm{p}<0.05)$. However, the resting tension was not significantly affected by L-NAME in SM (from $0.9 \pm 0.06$ to $0.9 \pm 0.07 \mathrm{~g}$; $n=5)$.

At resting tension, L-NAME almost abolished the relaxant response but enhanced the contractile response of LCV and $\mathrm{SCV}$ to $\mathrm{ACh}$ (fig. 3). Emax (but not $\mathrm{pD}_{2}$ ) for the contractile response was significantly different between the control and LNAME-treated groups (table 1). L-NAME had no significant affect on the contractile response of ACV, DNV, SPV and SM to $\mathrm{ACh}$; neither $\mathrm{pD}_{2}$ nor the Emax was significantly different between the control and L-NAME-treated group for these tissues (table 1).

At PE-raised tone, L-NAME markedly inhibited the relaxant response of LCV and SCV to ACh. L-arginine $\left(1 \times 10^{-2}-3 \times 10^{-2} \mathrm{M}\right)$ reversed this inhibitory effect (fig. 4). The Emax of the relaxation responses of $\mathrm{LCV}$ and SCV to ACh were obviously reduced with L-NAME treatment, but the reduction was almost abolished with addition of L-arginine. However, the $\mathrm{pD}_{2}$ values did not differ significantly between the control, L-NAME-treated and L-NAME+L-arginine treated groups (table 1).

\section{Immunohistochemical localisation of NOS in nasal venous vessels}

NADPH-diaphorase, a reliable marker for multiple isoforms of NOS in tissues after aldehyde fixation, was located in both the endothelial and tunica media of all nasal collecting and outflow veins, being most prominently stained in the LCV (fig. 5b), moderate in the ACV (fig. 5a) and weakest in the SPV (fig. 5c). Immunoreactivity to eNOS was also most salient in the LCV (fig. 6b) compared with other veins (figs 6a and c).

\section{DISCUSSION}

Previous in vivo studies have shown that $\mathrm{ACh}$, within physiological dose range, elicits nasal congestion at low doses but decongestion at high doses [4]. The current in vitro study investigated the actions of exogenous $\mathrm{ACh}$ on various segments of the nasal venous vascular bed to elucidate the vascular mechanisms underlying the biphasic nasal airway response.

At resting tension, ACh caused relaxation of LCV and SCV at concentrations $\leqslant 1 \times 10^{-3} \mathrm{M}$ but contraction of these vessels at higher concentrations, contraction of $\mathrm{ACV}, \mathrm{DNV}$ and SPV, and insignificant action on $\mathrm{SM}$ at all concentrations tested. At PEraised tone, the response patterns of the nasal venous vessels were similar except that the relaxations were bigger while the contractions were smaller or abolished. It is easier to elicit relaxation than contraction in blood vessels of raised tone, as the vascular smooth muscles are already considerably contracted.

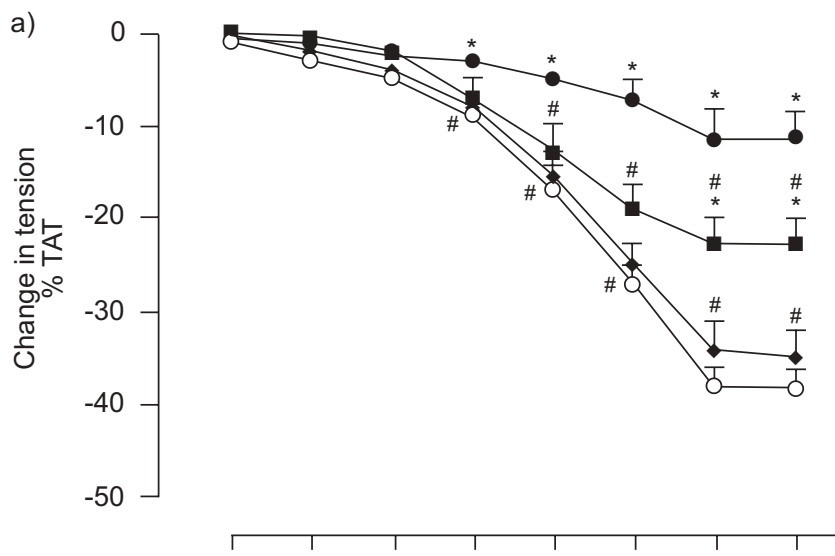

b)

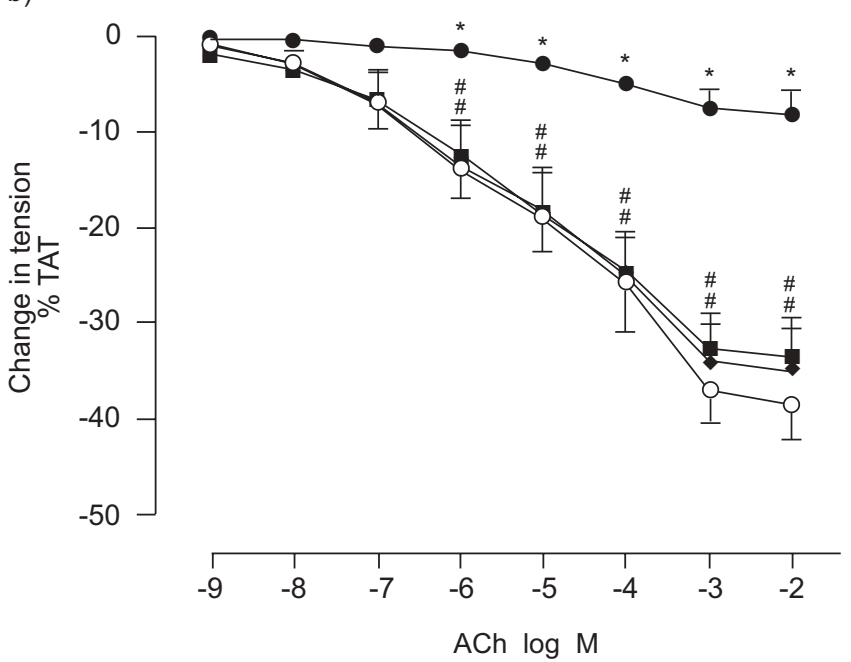

FIGURE 4. The effects of $10^{-5} \mathrm{M}$ nitro-L-arginine-methyl-ester (L-NAME) and $10^{-2} \mathrm{M}$ or $3 \times 10^{-2} \mathrm{M} \mathrm{L-arginine}$ on the responses of a) lateral collecting vein and $\mathrm{b}$ ) septal collecting vein to acetylcholine (ACh) at phenylephrine-raised tone. Data are presented as mean \pm SEM. TAT: total active tone. $O$ : control (a: $n=13 ; b: n=12$ ); $1 \times 10^{-5} \mathrm{M}$ L-NAME $(\mathrm{a}, \mathrm{b}: \mathrm{n}=5) ; \boldsymbol{\square}: 1 \times 10^{-5} \mathrm{M}$ L-NAME $+1 \times 10^{-2} \mathrm{M}$ L-arginine (a: $\mathrm{n}=5 ; \mathrm{b}: \mathrm{n}=7) ;: 1 \times 10^{-5} \mathrm{M}$ L-NAME $+3 \times 10^{-2} \mathrm{M}$ L-arginine $(\mathrm{a}, \mathrm{b}: \mathrm{n}=5) . *$ : $\mathrm{p}<0.05$ versus corresponding control; ${ }^{*}: p<0.05$ versus L-NAME-treated group. 

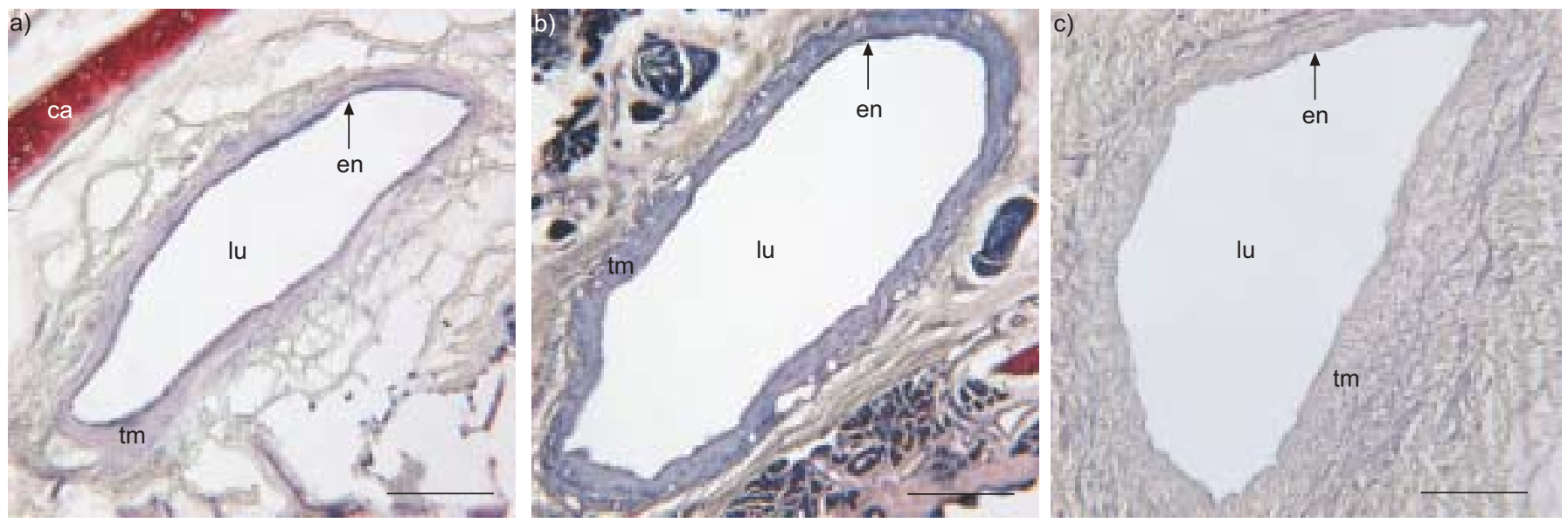

FIGURE 5. Immunohistochemical localisation of reduced nicotinamide adenine dinucleotide phosphate (NADPH)-diaphorase activities in a) the anterior collecting vein b) the lateral collecting vein, and c) the sphenopalatine vein. Positive NADPH-diaphorase activity is shown as a blue purple precipitate. en: endothelium; tm: tunica media; lu: vessel lumen; ca: cartilage. Scale bars: a) $200 \mu \mathrm{m}$; b) $500 \mu \mathrm{m}$; c) $300 \mu \mathrm{m}$.
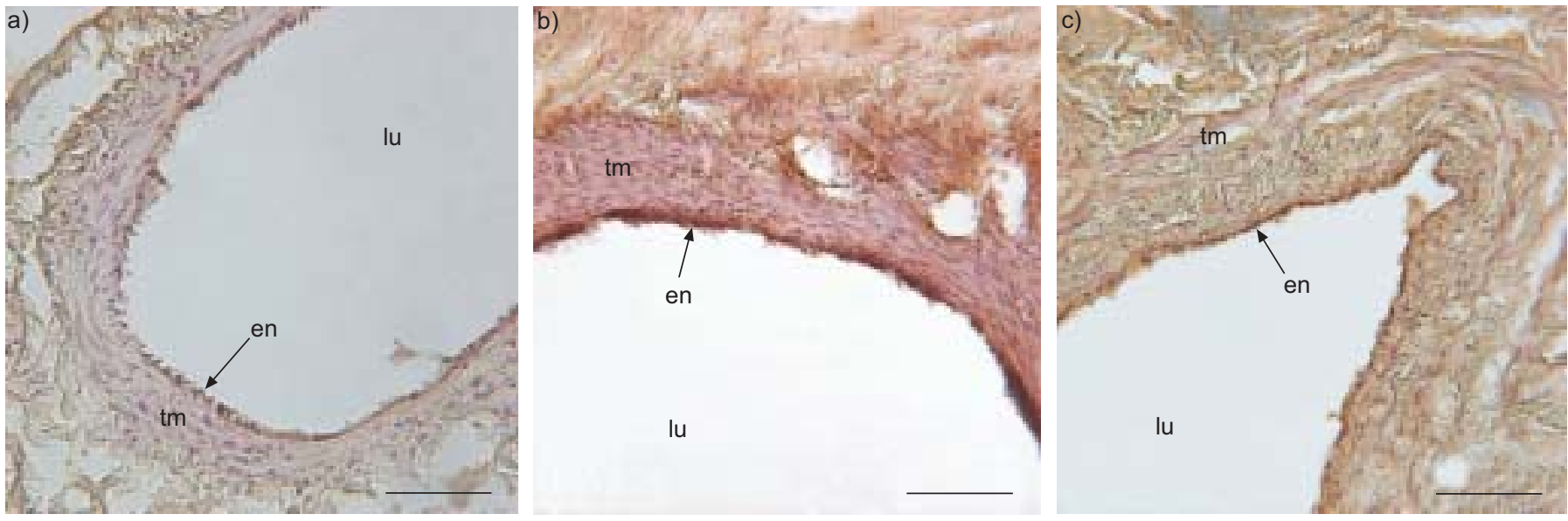

FIGURE 6. Immunohistochemical localisation of endothelial nitric oxide synthase (eNOS) in a) the anterior collecting vein, b) the lateral collecting vein, and c) the sphenopalatine vein. Positive eNOS activity is shown as a brown precipitate. en: endothelium; tm: tunica media; lu: vessel lumen. Scale bars: $50 \mu \mathrm{m}$.

ACh at lower concentrations $\left(\leqslant 1 \times 10^{-3} \mathrm{M}\right)$ relaxed the collecting veins (LCV and SCV) but contracted the outflow vein (SPV) of the posterior venous system. In vivo, relaxation of collecting veins increases vascular capacitance while contraction of the outflow vein prevents venous drainage. The two effects combined will cause blood congestion in the posterior venous system. At these concentrations, ACh also contracted both the collecting vein (ACV) and the outflow vein (DNV) of the anterior venous system. In vivo, if the entire anterior venous system contracts, blood will flow preferentially to the posterior venous system, which would aggravate the blood congestion there. The in vitro findings may explain why ACh in vivo at low doses $\left(<5 \mu \mathrm{g} \cdot \mathrm{kg}^{-1} \cdot \mathrm{min}^{-1}\right.$, intra-arterially) increases the nasal airway resistance and posterior venous outflow, but decreases the anterior venous outflow [4].

ACh at higher concentrations $\left(\geqslant 1 \times 10^{-2} \mathrm{M}\right)$ contracted the collecting and outflow veins of the two venous systems. Constriction of both collecting and outflow veins in vivo will decrease the mucosal blood volume. This may explain why
ACh decreases airway resistance at high doses $\left(>5 \mu \mathrm{g} \cdot \mathrm{kg}^{-1}\right.$. $\min ^{-1}$, intra-arterially) in vivo, whether the blood flow to the nose is allowed to increase spontaneously (due to dilatation of resistance vessels) or held constant (via controlled vascular perfusion) [4]. Contraction of all the collecting veins and outflow veins tends to empty the blood from the two nasal venous systems, increasing the venous output of the nose. This may be the reason why $\mathrm{ACh}$ at higher doses in vivo increases both venous outflows even in a nose with constant-flow vascular perfusion [4].

Previous in vivo animal studies have shown that N-nitro-Larginine, a NOS inhibitor, is effective in increasing nasal patency [14], suggesting the involvement of NO in basal nasal vascular regulation. The current authors showed that LNAME, another NOS inhibitor, increased the resting tension of LCV, SCV, ACV, SPV and DNV but not SM. This indicates $\mathrm{NO}$ involvement in the control of the resting vascular tone in both posterior and anterior venous systems but not in sinusoidal venous plexuses. The action of L-NAME on resting 
tone is larger in the posterior collecting veins (change of 45$63 \%$ in tone) than in other veins (change of $22-27 \%$ in tone), suggesting regional differences in NO's influence on the basal nasal venous tone, being pronounced in the posterior collecting veins but weaker in other veins. The results of histochemical localisation of NADPH-diaphorase have confirmed that NOS isoforms are differentially distributed in various nasal venous vessels, being most prominent in the posterior collecting veins (fig. 5). Likewise, eNOS immunoreactivity is strongest in the posterior collecting veins (fig. 6). Using acoustic rhinometry, SILKOFF et al. [15] reported that topical application of L-NAME has no effect on nasal patency in humans. A drug given topically as an aerosol will tend to stay in the anterior nasal cavity rather than reaching the less accessible posterior nasal cavity. The current study shows that the influence of $\mathrm{NO}$ on resting venous tone and eNOS immunoreactivity is felt primarily in the posterior collecting veins. Moreover, acoustic rhinometry, which monitors the minimal cross-section of the anterior nasal cavity at the nasal valves, has limitations in assessing patency changes posterior to the anterior nasal valve.

The relaxant responses of posterior collecting veins to ACh were inhibited by L-NAME and the inhibitory effect of LNAME was antagonised by an NO precursor, L-arginine, indicating that the relaxant responses are related to $\mathrm{NO}$ synthesis. The contractile responses of ACV, DNV and SPV to ACh were unaffected by L-NAME but the contractile response of posterior collecting veins was enhanced, suggesting that the ACh-induced contraction is independent of the NO pathway but it can be modified by $\mathrm{NO}$ in the posterior collecting veins. The latter finding implies a relatively more pronounced influence of NO in posterior collecting veins than in other veins. This is in accordance with the pattern of regional distribution of NOS/eNOS immunoreactivity in the nasal venous vasculature, being most pronounced in the posterior collecting veins. Thus, the current in vitro study has demonstrated clearly that there are regional differences in NOdependent relaxation responses to $\mathrm{ACh}$ in the nasal venous vasculature. Similar results have been found in the other venous vessels of $\mathrm{dog}$, such as external jugular vein, superior and inferior vena cavae, and brachiocephalic vein [16], while LACROIX et al. [17] reported that NOS inhibition does not modify the nasal vascular conductance to ACh in vivo. Vascular conductance depends primarily on the tone of the resistance vessels rather than on that of the venous vessels.

In the current authors' preparation, with nicotinic receptors being blocked by hexamethonium in the tissue bath, ACh can only elicit vascular response via activation of muscarinic receptors. The effects at low concentrations probably represent the actions of $\mathrm{ACh}$ in physiological or pathophysiological situations while those at high concentrations are most likely pharmacological effects. An increase in the number of muscarinic receptors has been found in the nasal mucosa of human and animal models with nasal allergy [18, 19]. It is highly probable that the pathogenesis of hyper-reactive nasal symptoms may be associated partly with the differential changes in the number or the reactivity of muscarinic receptors in different segments of the venous vascular bed. Activation of muscarinic receptors in the posterior collecting veins will increase vascular capacitance, while activation of muscarinic receptors in the outflow veins will impair venous drainage. Both mechanisms acting together can easily promote nasal congestion, especially when the number and/or reactivity of the muscarinic receptors is increased. Radiolabelled ligand binding, autoradiography, competitive binding analysis and immunological studies suggest that muscarinic receptor subtypes are present in the sinusoidal blood vessels of human inferior turbinate mucosa $[20,21]$. Further studies are required to characterise the muscarinic receptor subtype(s) present on the collecting and outflow veins of the nasal venous systems.

The human nasal mucosa shows prominent similarities with the canine nasal mucosa: cavernous venous plexuses; muscular collecting veins (cushion or throttle veins); anterior venous drainage via dorsal nasal vein; and posterior venous drainage via the sphenopalatine vein [1]. It is probable that results from the current study are applicable to human nasal mucosa. Hence, the development of highly selective antagonists for the muscarinic receptor subtype(s) present on the nasal collecting and outflow veins have potential to be of great therapeutic value in the treatment of congestion in hyperreactive nasal mucosa.

\section{ACKNOWLEDGEMENTS}

The authors would like to thank J.C.C. Wang and C.H. Lai for their helpful comments, K.K. Tsang and K. Tsang for technical assistance, the Laboratory Animal Unit at Hong Kong University and the Agriculture, Fisheries and Conservation Dept of the Hong Kong SAR government for supplying experimental animals.

\section{REFERENCES}

1 Cauna N. Blood and nerve supply of the nasal lining. In: Proctor DR, Andersen IB, eds. The Nose-Upper Airway Physiology and the Atmospheric Environment. Amsterdam, Elsevier, 1982; pp. 45-69.

2 Lung MA, Wang JCC. Arterial supply, venous drainage and collateral circulation in the nose of the anaesthetized dog. J Physiol 1987; 391: 57-70.

3 Lung MA, Wang JCC. An anatomical investigation of the nasal venous vascular bed in the dog. J Anat 1989; 166: 113-119.

4 Lung MA, Wang JCC. Increase or decrease in nasal airway resistance induced by acetylcholine in anesthetized dogs: vascular mechanisms. Ann Otol Rhinol Laryngol 1994; 103: 646-651.

5 Wang M, Lung MA. Adrenergic mechanisms in canine nasal venous systems. Br J Pharmacol 2003; 138: 145-155.

6 Thuerauf N, Kaegler M, Dietz R, Barocka A, Kobal G. Dose-depedent stereoselective activation of the trigeminal sensory system by nicotine in man. Psychopharmacology 1999; 142: 236-243.

7 Macklin KD, Maus ADJ, Pereira EFR, Albuquerque EX, Conti-Fine BM. Human vascular endothelial cells express functional nicotinic acetylcholine receptors. J Pharmacol Exp Ther 1998; 287: 435-439.

8 Brimijoin S, Skau K, Wiermaa MJ. On the origin and fate of external acetylcholinesterase in peripheral nerve. J Physiol (Lond) 1978; 285: 143-158. 
9 O'Rourke ST, Vanhoutte PM. Adrenergic and cholinergic responsiveness of isolated canine bronchial arteries. Am J Physiol 1990; 259: H156-H161.

10 Modin A, Bjorne H, Herulf M, Alving K, Weitzberg E, Lundberg JO. Nitrite-derived nitric oxide: a possible mediator of "acidic-metabolic" vasodilatation. Acta Physiol Scand 2001; 171: 9-16.

11 Dear JW, Ghali S, Foreman JC. Attenuation of human nasal airway responses to bradykinin and histamine by inhibitors of nitric oxide synthase. Br J Pharmacol 1996; 118: 1177-1182.

12 Drummond GR, Cocks TM. Endothelium-dependent relaxations mediated by inducible $B_{1}$ and constitutive $B_{2}$ kinin receptors in the bovine isolated coronary artery. $\mathrm{Br} \mathrm{J}$ Pharmacol 1995; 116: 2473-2481.

13 Lincoln J, Hoyle CHV, Burnstock G. Nitric Oxide in Health and Disease. Cambridge, Cambridge University Press, 1997; pp. 244-257.

14 Rinder J, Lundberg JM. Nasal vasoconstriction and decongestion effects of nitric oxide synthase inhibition in the pig. Acta Physiol Scand 1996; 157: 233-244.

15 Silkoff PE, Roth Y, McClean P, Cole P, Chapnik J, Zamel N. Nasal nitric oxide does not control basal nasal potency or acute congestion following allergen challenge in allergic rhinitis. Ann Otol Rhinol Laryngol 1999; 108: 368-372.
16 Furuta T, Shigei T. A regional difference in endotheliumdependent relaxation responses to acetylcholine in the canine venous system. Jpn J Pharmacol 1987; 44: 207-210.

17 Lacroix JS, Potter EK, Mclachlan E. Nitric oxide and parasympathetic vascular and secretory control of the dog nasal mucosa. Acta Otolaryngol 1998; 118: 257-263.

18 Ando H, Terada N, Togawa K, Konno A. The relationship between the number of the autonomic nerve receptors and degree of hyperreactive nasal symptoms in patients with hyperesthetic rhinitis. Nippon Jibiinkoka Gakkai Kaiho 1989; 92: 183-188.

19 Naminatsu A, Okazaki R, Go K, Hata T. Relationship between density of muscarinic receptors and nasal hypersecretion in a nasal allergic model. Jpn J Pharmacol 1992; 59: 427-437.

20 Okayama M, Mullol J, Baraniuk JN, et al. Muscarinic receptor subtypes in human nasal mucosa: characterization, autographic localization and function in vitro. Am J Respir Cell Mol Biol 1993; 8: 176-187.

21 Nakaya M, Yuasa $T$, Usui N. Immunohistochemical localization of subtypes of muscarinic receptors in human inferior turbinate mucosa. Ann Otol Rhinol Laryngol 2002; 111: 593-597. 